University of Nebraska - Lincoln

DigitalCommons@University of Nebraska - Lincoln

Agronomy \& Horticulture -- Faculty Publications

Agronomy and Horticulture Department

2006

\title{
Evaluation of the Single Kernel Characterization System (SKCS) for Measurement of Sorghum Grain Attributes
}

\author{
S. R. Bean \\ USDA-ARS \\ O. K. Chung \\ USDA-ARS \\ M. R. Tuinstra \\ Kansas State University \\ Jeffrey F. Pedersen \\ University of Nebraska-Lincoln, jpedersen1@unl.edu \\ J. Erpelding \\ USDA-ARS
}

Follow this and additional works at: https://digitalcommons.unl.edu/agronomyfacpub

Part of the Agricultural Science Commons, Agriculture Commons, Agronomy and Crop Sciences Commons, Botany Commons, Horticulture Commons, Other Plant Sciences Commons, and the Plant Biology Commons

Bean, S. R.; Chung, O. K.; Tuinstra, M. R.; Pedersen, Jeffrey F.; and Erpelding, J., "Evaluation of the Single Kernel Characterization System (SKCS) for Measurement of Sorghum Grain Attributes" (2006). Agronomy \& Horticulture -- Faculty Publications. 930.

https://digitalcommons.unl.edu/agronomyfacpub/930

This Article is brought to you for free and open access by the Agronomy and Horticulture Department at DigitalCommons@University of Nebraska - Lincoln. It has been accepted for inclusion in Agronomy \& Horticulture -Faculty Publications by an authorized administrator of DigitalCommons@University of Nebraska - Lincoln. 


\title{
Evaluation of the Single Kernel Characterization System (SKCS) for Measurement of Sorghum Grain Attributes
}

\author{
S. R. Bean, ${ }^{1,2}$ O. K. Chung, ${ }^{1}$ M. R. Tuinstra, ${ }^{3}$ J. F. Pedersen, ${ }^{4}$ and J. Erpelding ${ }^{5}$
}

The single kernel characterization system (SKCS) has been widely used in the wheat industry, and SKCS parameters have been linked to end-use quality in wheat. The SKCS has promise as a tool for evaluating sorghum grain quality. However, the SKCS was designed to analyze wheat, which has a different kernel structure from sorghum. To gain a better understanding of the meaning of SKCS predictions for grain sorghum, individual sorghum grains were measured for length, width, thickness (diameter), and weight by laboratory methods and by the SKCS. SKCS predictions for kernel weight and thickness were highly correlated to laboratory measurements. However, SKCS predictions for kernel thickness were underestimated by $\approx 20 \%$. The SKCS moisture prediction for sorghum was evaluated by tempering seven samples with varying hardness values to four moisture levels. The moisture contents predicted by SKCS were compared with a standard oven method and, while correlated, SKCS moisture predictions were less than moisture measured by air oven, especially at low moisture content. Finally, SKCS hardness values were compared with hardness measured by abrasive decortication. A moderate $(r=0.67, P<0.001)$ correlation was observed between the hardness measurements. The SKCS predictions of kernel weight and diameter were highly correlated with laboratory measurement. Moisture prediction, however, was substantially lower by the SKCS than as measured by an air oven method. The SKCS should be suitable for measuring sorghum grain attributes. Further research is needed to determine how SKCS hardness predictions are correlated to milling properties of sorghum grain.
Grain hardness or endosperm texture (grain strength) is an important grain quality attribute that plays a role in the processing of cereal grains and in the end-use quality of cereal grain products such as breads and snack foods (Cagampang and Kirleis 1984; Bettge and Morris 2000). Grain hardness also plays a role in plant defense against molds and possibly from insect attack (Chandrashekar and Mazhar 1999).

For sorghum, grain hardness has been linked to a number of specific end-use quality traits. Cagampang and Kirleis (1984) reported that sorghum cooking quality parameters such as adhesion, cooked grain texture, alkali gel stiffness, and amylograph viscosities were significantly related to grain hardness. Rooney et al (1986) reported that sorghum grain hardness was the most important component related to porridge quality. Grain hardness was also related to the production of high-quality couscous granules from sorghum (Aboubacar and Hamaker 1999). Within a given grain lot, large sorghum kernels were harder than small kernels and related to higher quality grain (Lee et al 2002). Milling quality of sorghum grain has been related to grain hardness as well (Maxson et al 1971; Munck et al 1981; Munck 1995; Rooney and Waniska 2000). Grain hardness has also been linked to mold and weathering resistance in sorghum (Jambunathan et al 1992; Kumari and Chandrashekar 1994; Audilakshimi et al 1999; Waniska 2000).

To measure grain hardness in sorghum, a number of different methods have been used. Pomeranz (1986) used the Brabender hardness tester, Stenvert micro-hammermill test, particle size index, and near-infrared reflectance to determine sorghum grain hardness. Lawton and Faubion (1989) reported the sorghum milling data using the tangential abrasive dehulling device

\footnotetext{
${ }^{1}$ USDA-ARS, Grain Marketing and Production Research Center, Manhattan, KS 66502. Names are necessary to report factually on available data; however, the USDA neither guarantees nor warrants the standard of the product, and the use of the name by the USDA implies no approval of the product to the exclusion of others that may also be suitable.

${ }^{2}$ Corresponding author. Phone: 785-776-2725. Fax: 785-537-5534. E-mail: scott.bean@gmprc.ksu.edu

${ }^{3}$ Kansas State University, Dept. of Agronomy, Manhattan, KS 66506.

${ }^{4}$ USDA-ARS, Wheat, Sorghum, and Forage Research, Lincoln, NE 68583-0937.

${ }^{5}$ USDA-ARS Tropical Agriculture Research Station, Mayaguez, Puerto Rico.
}

DOI: $10.1094 / C C-83-0108$

This article is in the public domain and not copyrightable. It may be freely reprinted with customary crediting of the source. AACC International, Inc., 2006.
(TADD) followed the first-order rate loss function. They used these data to categorize 13 sorghum hybrids into seven hardness groups. Perhaps the most widely used method for measuring grain hardness and relating it to milling performance in sorghum is the tangential abrasive dehulling device (Rooney and Waniska 2000).

The single kernel characterization system (SKCS) has also been used to measure grain hardness in sorghum (Pedersen et al 1996). These authors analyzed grains from 64 sorghum genotypes using a prototype SKCS instrument and compared the hardness values with seed vitreousness. SKCS hardness values were correlated $(r$ $=0.75$ ) to percent vitreousness in sorghum. Also, SKCS diameter and weight predictions were compared with laboratory measurements as well as with density measurements. The SKCS predictions for diameter and weight were highly correlated to laboratory measurements, though SKCS underestimated kernel diameter.

The SKCS, which was designed to analyze wheat, works by crushing individual grains between a serrated rotor and a crescent (Martin et al 1993; Martin and Steele 1996). Typically 300 kernels are analyzed per sample. Both the average and the standard deviations for the 300 kernels are reported. As noted by Pedersen et al (1996), the standard deviations reported by the SKCS for a given sample may also be useful information for sorghum by providing a measure of sample uniformity.

Kernel hardness is determined from formulas developed by Martin et al (1993) using various instrument parameters and moisture and diameter. It is important to note that the four parameters predicted by SKCS are all indirect and must be calibrated against standard methods (Osborne and Anderssen 2003). An excellent overview on the operation and principles of the SKCS is presented in Osborne and Anderssen (2003). These authors also review the applications of SKCS in wheat research and the wheat industry as well as the use of SKCS for nonwheat cereals.

Pedersen et al (1996) demonstrated that SKCS could successfully analyze sorghum grain. However, the sorghum kernel is substantially different in shape than wheat, the grain for which the instrument was originally designed, which could cause uncertainty in relating SKCS predictions to sorghum grain. For example, Pedersen et al (1996) reported that SKCS underestimated kernel diameter in sorghum. Thus the goals of this study were to evaluate SKCS predictions of hardness, weight, moisture, and diameter of sorghum kernels and compare them with traditional methods for obtaining these measurements and, if necessary, to develop new slope and bias adjustments to improve their accuracy. 
A secondary goal was to compare SKCS hardness values with abrasive hardness values, one of the more widespread direct methods for measuring sorghum grain hardness.

\section{MATERIALS AND METHODS}

\section{Samples}

Sorghum grain samples were obtained from university and federal sorghum breeding programs as well as the sorghum collection maintained by U.S. National Plant Germplasm System. Samples were selected to evaluate a wide range of genetic and phenotypic diversity. This sample set encompassed a range of physical properties (Table I) as well as tannin sorghums, waxy sorghums, and heterowaxy sorghums.

\section{Measurements}

Individual grains were weighed using an analytical balance (AND HR-60) and diameter measured using digital calipers (Digimatic, Mitutoyo Corporation, Kanagawa, Japan). Image analysis was used to measure length and width of grains. Whole grains were scanned into the computer using a flatbed scanner (Perfection 3200 Photo, Epson) and the computer program Sigma Scan Pro5 (Systat Software, Richmond, CA) was used to measure the length (defined as the distance from the style to the top of the kernel) and width (defined as perpendicular to the axis of the length).

Moisture of whole grain sorghum was determined using the single-stage air oven method (Hart et al 1959; ASAE 2003). This method utilizes whole grain dried for $18 \mathrm{hr}$ at $130^{\circ} \mathrm{C}$ to determine the moisture content. Seven sorghum samples varying in SKCSHI of 34-109 were equilibrated to four different moisture levels $(\approx 8,10,13$, and $16 \%)$ using the method of Martin et al $(1993)$. Briefly, samples of known moisture were placed in a dessicator chamber humidified with water at room temperature. Samples were periodically removed and weighed until at approximately the correct moisture content. Samples were then removed and stored in sealed jars for $24 \mathrm{hr}$ before measuring the moisture using the air oven method described above. In some cases, it was necessary to dry samples to achieve low moisture levels. Samples were dried by spreading grain out in a single layer and air was circulated over them with a fan. Heat was not used to dry the samples.

SKCS hardness measurements of samples were analyzed using a SKCS 4100 (Perten Instruments) controlled by the MicroSoft Windows software SK4100, v. 2,1,0,1. Samples were cleaned before analysis by sieving over a screen with $2.0-\mathrm{mm}$ triangular openings (B-P triangle screen, Seedburo Equipment Company, Chicago, IL). Glumes, broken kernels, and foreign matter were removed by hand if necessary (Pedersen et al 1996).

Abrasive hardness index (AHI) was determined using a TADD (Venebles Machine Works, Saskatoon, Canada) as described in Oomah et al (1981). An 80-grit abrasive, supplied by the manufacturer, was used on the TADD and the TADD was shimmed so that there was minimal distance between the abrasive and the bottom of the wells on the TADD. A control sorghum hybrid was analyzed every 16 runs on the TADD to monitor the performance

TABLE I

Physical Attributes of Sorghum Grain Samples

\begin{tabular}{lcccc}
\hline & SKCS-HI $^{\mathbf{a}}$ & AHI $^{\mathbf{b}}$ & $\begin{array}{c}\text { Kernel Dia } \\
(\mathbf{m m})^{\mathbf{c}}\end{array}$ & $\begin{array}{c}\text { Kernel Wt } \\
(\mathbf{m g})^{\mathbf{d}}\end{array}$ \\
\hline Mean & 77.5 & 11.2 & 2.2 & 26.3 \\
Min & 36.5 & 6.4 & 1.4 & 16.6 \\
Max & 110.7 & 22.0 & 2.8 & 36.9 \\
SD & 17.6 & 3.0 & 0.3 & 5.5 \\
\hline
\end{tabular}

a Single kernel characterization system hardness index (SKCS-HI) determined under optimized conditions.

${ }^{\mathrm{b}}$ Abrasive hardness index.

${ }^{\mathrm{c}}$ Determined using SKCS.

d Determined using SKCS. of the abrasive disk. When AHI of the control began to vary by $>5 \%$, the abrasive disk was replaced.

\section{RESULTS AND DISCUSSION}

\section{Kernel Weight Prediction}

The accuracy of the SKCS for predicting kernel weight of sorghum was assessed by weighing individual sorghum kernels and then analyzing them one at a time with the SKCS. SKCS predictions of weight were essentially identical to the weights as measured on an analytical balance $\left(R^{2}=0.99, P<0.0001, n=54\right)$ (Fig. 1). Therefore no slope and bias adjustments for kernel weight were necessary. This confirms the results of Pedersen et al (1996), who also found that SKCS kernel weights from a prototype instrument closely matched those weighed using a balance.

\section{Kernel Diameter Prediction}

The SKCS was designed to analyze wheat kernels, which have a substantially different structure than sorghum kernels. Sorghum kernels are generally referred to as round, but in fact most have a flat surface on the sides of the kernel; only $0.6 \%$ out of 1,768 sorghum lines were found to have round kernels (Reichart et al 1988). Thus sorghum grains have a diameter, or perhaps more correctly, a thickness, a length, and a width. Because SKCS kernel diameter is influenced by the geometry of the kernel and how it passes through the rotor and crescent (Osborne and Anderssen 2003), the diameter predictions of the SKCS for sorghum could be related to thickness (diameter), length, width, or a combination of these measurements. To determine which kernel dimension the SKCS was actually predicting, measurements on individual sorghum kernels were made and then analyzed individually on the SKCS. The results are shown in Fig. 2. The thickness (diameter) of the sorghum kernels, as measured by digital calipers, was highly correlated to SKCS predictions of diameter, while length and width measurements were not. Thus SKCS prediction of diameter does relate to the diameter, or thickness, of the sorghum kernel. The default settings of the SKCS (set for wheat kernels) tended to underestimate the diameter as measured by digital calipers. This was also reported by Pedersen et al (1996). Using a larger data set $(n=323)$, it was also possible to develop improved slope and bias adjustments for SKCS prediction $\left(R^{2}=0.92, P<\right.$ $0.0001)$ of diameter relative to diameter as measured by digital calipers (Fig. 3).

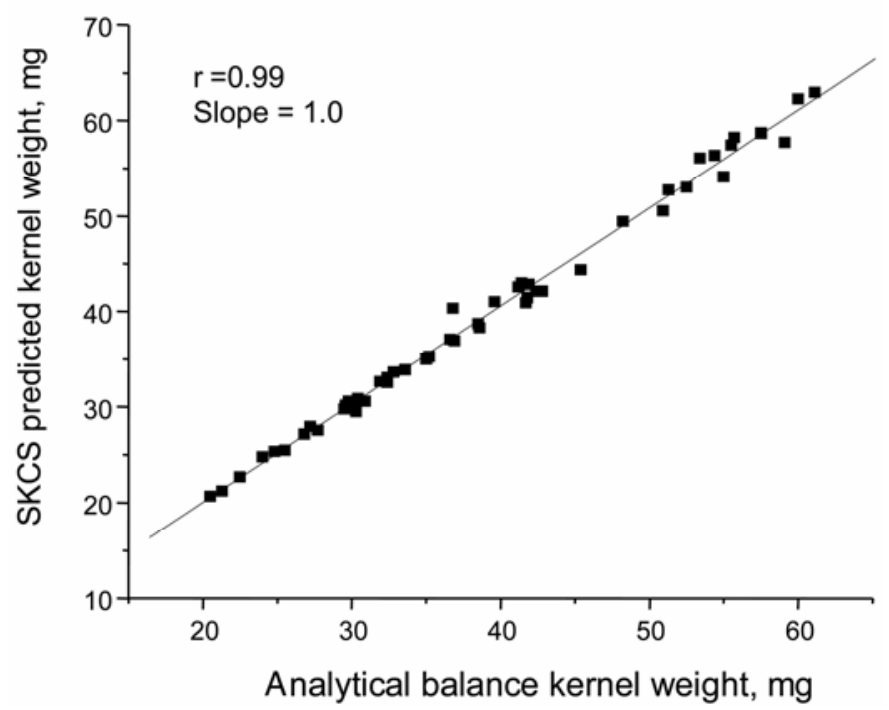

Fig. 1. Scatter plot showing correlation between sorghum kernel weight as measured on an analytical balance and kernel weight predicted by the single kernel characterization system (SKCS). 


\section{Kernel Moisture Prediction}

Kernel moisture can also be predicted by SKCS. Electrical conductance of the grains is measured at the time of maximum crush force and, along with force terms, it is used to predict the moisture content (Osborne and Anderssen 2003). Because sorghum and wheat kernels differ substantially, it is reasonable to conclude that the factory calibrations for wheat moisture will be
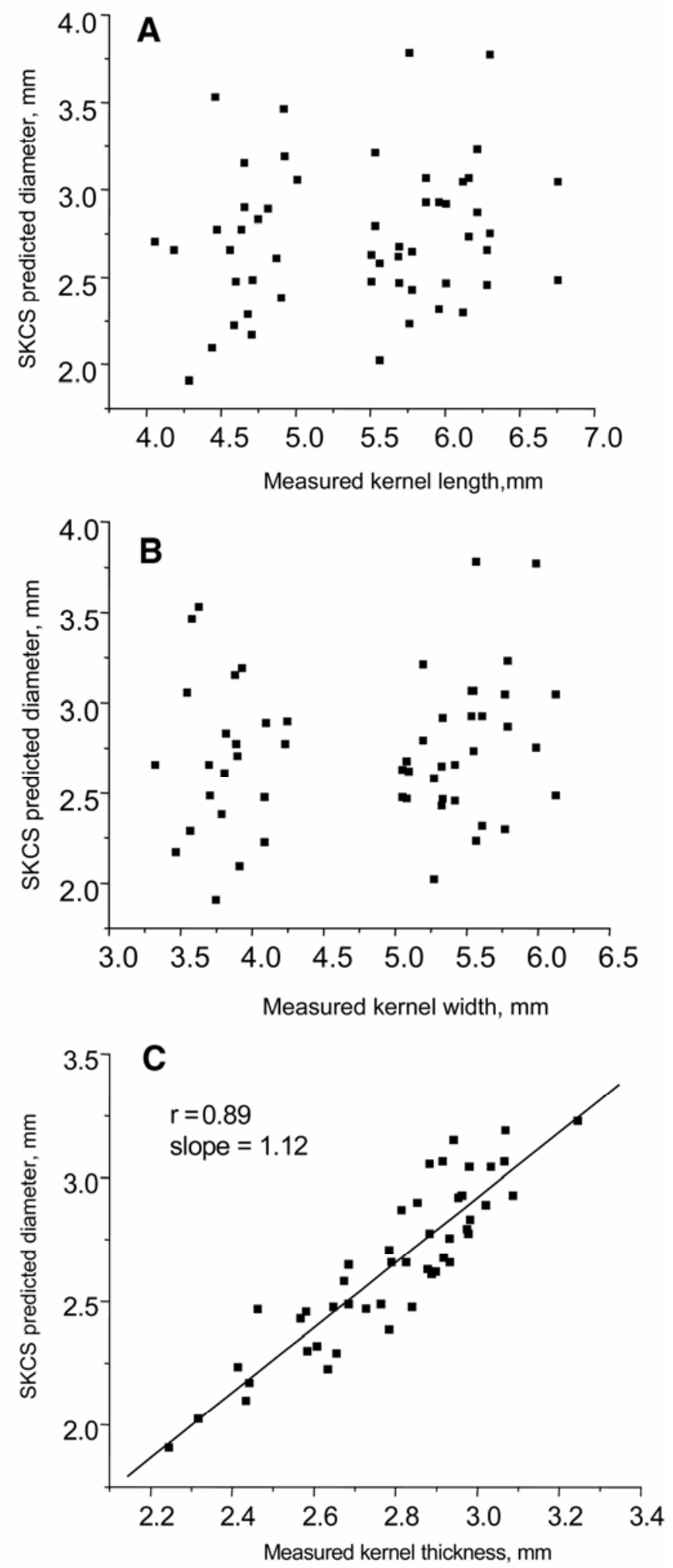

Fig. 2. Scatter plots showing correlations between length (A), width (B), and diameter (thickness) (C) of sorghum kernels and kernel diameter predicted by the single kernel characterization system (SKCS). inaccurate for predicting sorghum moisture. To evaluate the moisture prediction of sorghum by SKCS, six sorghum hybrids were adjusted to four different moisture levels and analyzed by SKCS. SKCS moisture predictions were substantially lower than the air oven moistures measured on these samples $\left(R^{2}=0.96, P<0.001\right.$, $n=28$ ) (Fig. 4). Used with the default moisture slope and bias, SKCS tended to predict moisture contents lower than that measured using an air oven method. New slope and bias numbers to correct this were obtained from the data in Fig. 4. To test the effect of the slope and bias corrections on the moisture prediction, one sorghum sample was adjusted to four different moisture levels and the moisture measured using the air oven method and on the SKCS using both the factory default slope and bias and the new slope and bias obtained from the data in Fig. 4. Moisture content predicted by SKCS was closer to, but still different than, the air oven moisture measurements after the new slope and bias adjustments were made (Table II). A greater number of samples should be used to develop a more robust slope and bias correction if the SKCS is to be used to routinely predict moisture in sorghum. SKCS moisture predictions for barley also had lower correlations $(r=$ 0.71 ) than that typically found with wheat (Panozzo and Ratcliffe 1997).

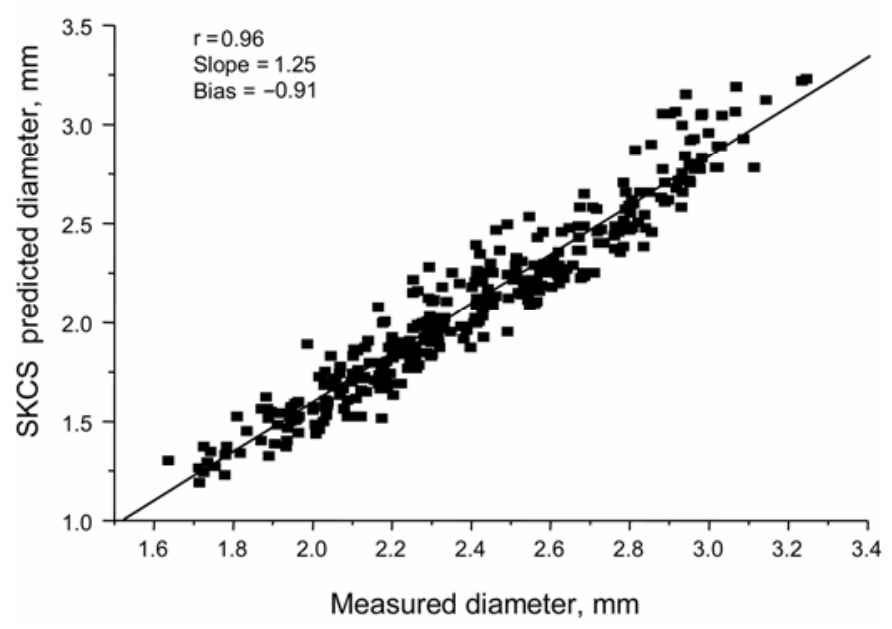

Fig. 3. Scatter plot used to determine slope and bias adjustments for correcting diameter as measured by digital calipers to diameter predicted by the single kernel characterization system (SKCS). Correlation coefficient, slope, and bias numbers as shown.

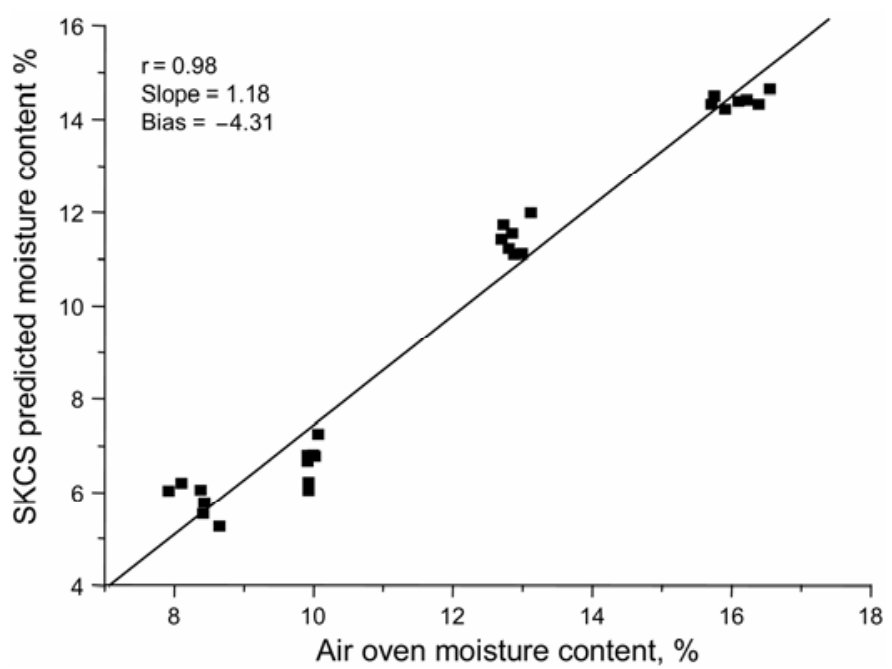

Fig. 4. Scatter plot showing correlation between air oven moisture content $(\%)$ and moisture content $(\%)$ predicted by the single kernel characterization system (SKCS). Correlation coefficient, slope, and bias numbers as shown. 


\section{Kernel Rejection Criteria}

The next step was to develop new kernel rejection criteria. Kernel rejection criteria were determined by plotting SKCS kernel weight versus SKCS kernel diameter for individual kernels $\left(R^{2}=\right.$ 0.77, $P<0.0001, n=323$ ) (Fig. 5). Improved kernel rejection criteria may help eliminate the picking up of doubles (two kernels at one time) reported by Pedersen et al (1996). The new slope and bias adjustments for kernel rejection criteria are shown in Fig. 5. For comparison, the factory default kernel rejection criteria were slope 1.448 and bias 1.887 .

Note that when using the SKCS software running in Microsoft Windows, it is possible to select the vacuum used to pick up samples by the singulator wheel. For most sorghum samples, we found that the default vacuum setting was adequate. However, when analyzing samples with very large kernels $(\geq 40 \mathrm{mg})$, the vacuum had to be increased to a setting of 850 or a large number of kernels were not picked up by the singulator wheel. Conversely, when analyzing very small sorghum grains, the standard vacuum setting sometimes picked up doubles as reported by Pedersen et al (1996). Reducing the vacuum setting helped to greatly reduce this problem.

\section{Comparison of SKCS Hardness vs. AHI}

Finally, SKCS hardness values were compared with AHI (Fig. 6). In general, SKCS and AHI values agreed and showed the same trend; samples with low AHI values also had low SKCS values, however the correlation between the two techniques was low $\left(R^{2}\right.$ $=0.45, P<0.0001, n=100)$. Preliminary data from Awika et al

TABLE II

Example of Moisture Correction with New Slope and Bias Adjustments

\begin{tabular}{|c|c|c|c|}
\hline \multirow[b]{3}{*}{ Sample } & \multicolumn{3}{|c|}{ Moisture Content (\%) } \\
\hline & \multicolumn{2}{|c|}{ Preadjustment $^{\mathrm{a}}$} & \multirow{2}{*}{$\frac{\text { Postadjustment }^{\mathrm{b}}}{\text { SKCS }}$} \\
\hline & Air Oven & $\mathbf{S K C S}^{\mathrm{c}}$ & \\
\hline 1 & 8.9 & 6.1 & 8.6 \\
\hline 2 & 10.9 & 7.8 & 9.5 \\
\hline 3 & 12.8 & 10.9 & 11.5 \\
\hline 4 & 15.7 & 13.8 & 14.4 \\
\hline
\end{tabular}

a Determined using factory default slope and bias settings.

b Determined with optimized slope and bias settings.

c Single kernel characterization system (SKCS).

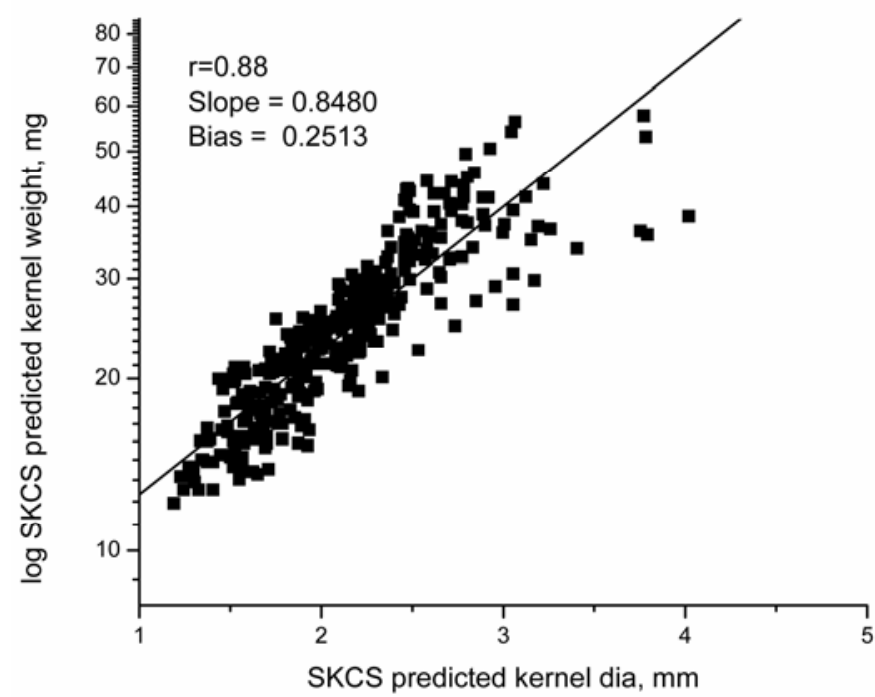

Fig. 5. Scatter plot of log for single kernel characterization system (SKCS) predicted kernel diameter ( $\mathrm{mm})$ vs. SKCS predicted kernel weight $(\mathrm{mg})$ to develop new slope and bias corrections for kernel rejection criteria. Correlation coefficient, slope, and bias numbers as shown.
(2002) reported similar relationships between SKCS and AHI. Pedersen et al (1996) reported similar relationships $(r=0.70)$ to percent vitreousness in sorghum, which is an indirect measure of hardness in sorghum.

To examine the relationship between SKCS-HI and AHI, data were divided into four classes for both kernel size and weight and the correlation between SKCS-HI and AHI for these subclasses was determined. For kernel weight, the highest correlation between SKCS-HI and AHI was obtained for kernels weighing 21-25.9 mg (Table III) $(r=0.79, P<0.0001)$. For the remaining weight classes, the correlations between SKCS-HI and AHI were similar to each other, with the lowest being found with kernels weighing 26-30.9 mg $(r=0.59, P<0.001)$. For kernel diameter, the highest correlation between SKCS-HI and AHI was found with kernels $1.8-2.1 \mathrm{~mm}(r=0.075, P<0.001)$ (Table IV).

It was interesting that kernel weight and diameter subclasses that had the highest correlations between SKCS-HI and AHI had broad ranges of hardness values (Tables III and IV). That is, the correlations were not confined to a certain range of hardness values. It was also interesting that the kernel diameter subclass with the highest correlation between SKCS-HI and AHI included a large range of kernel weights, and vice versa. This suggests that other factors such as kernel shape, pericarp thickness, etc., may be responsible for variability between SKCS-HI and AHI. The abrasive action of the TADD is substantially different than the crushing method used by the SKCS. Abrasive hardness measurements can be influenced by kernel shape, kernel size, and pericarp thickness (Kirleis and Crosby 1982; Lawton and Faubion 1989). Hardness measurements in general can be influenced by kernel morphology (Pomeranz 1986) and previous investigations of the correlation between different sorghum hardness indices have shown variability, though many of the tests rank sorghum samples the same in terms of hardness (Kirleis and Crosby 1982; Pomeranz 1986; Pedersen et al 1996). Thus it is not surprising that the SKCS-HI and AHI differ somewhat.

It would be possible to develop slope and bias corrections for SKCS to predict AHI values (using AHI as the hardness reference for the SKCS). However, as SKCS-HI generally showed the same trend as AHI values, this was not done. Furthermore, as SKCS-HI is determined by a different method than AHI (crushing vs. abrasion), SKCS-HI may have different correlations to end-use quality traits than AHI. Until it can be determined how SKCS-HI values relate to processing and end-use traits in sorghum and how

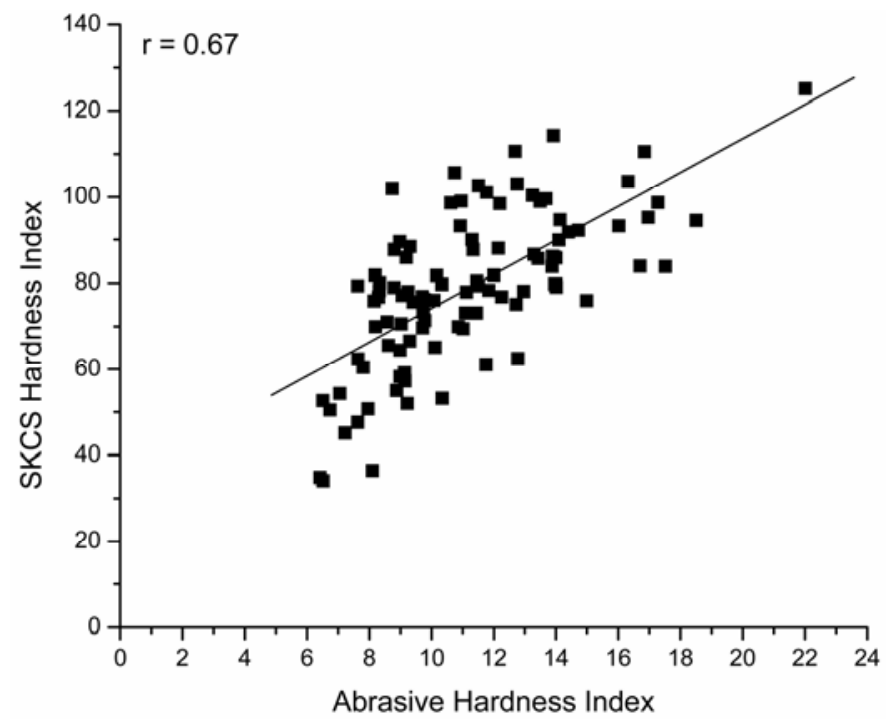

Fig. 6. Scatter plot showing the correlation between abrasive hardness index determined by the tangential abrasive dehulling device (TADD) and the single kernel characterization system (SKCS) hardness index. 
TABLE III

Correlations Between Single Kernel Characterization System Hardness Index (SKCS-HI) and Abrasive Hardness Index (AHI) for Kernel Weight Subclasses

\begin{tabular}{|c|c|c|c|c|}
\hline & \multicolumn{4}{|c|}{ Weight Subclasses } \\
\hline & $16-21.9 \mathrm{mg}$ & $22-25.9 \mathrm{mg}$ & $26-30.9 \mathrm{mg}$ & $>31 \mathrm{mg}$ \\
\hline$r^{\mathrm{a}}$ & $0.69 * *$ & $0.79 * *$ & $0.59 *$ & $0.69 *$ \\
\hline AHI range ${ }^{b}$ & $7-22$ & $6-17$ & $7-16$ & $7-18$ \\
\hline AHI average & 12 & 11 & 11 & 11 \\
\hline $\mathrm{SKCS}$ range $^{\mathrm{c}}$ & $36-125$ & $35-111$ & 34-94 & $45-92$ \\
\hline SKCS average & 87 & 78 & 75 & 72 \\
\hline Diameter range $(\mathrm{mm})^{\mathrm{d}}$ & $1.4-2.0$ & $1.8-2.5$ & $2.0-2.5$ & $2.2-2.8$ \\
\hline Diameter average $(\mathrm{mm})$ & 1.8 & 2.0 & 2.3 & 2.5 \\
\hline$n^{\mathrm{e}}$ & 33 & 22 & 27 & 19 \\
\hline
\end{tabular}

a Correlation between SKCS-HI and AHI: ** and * indicate $P<0.0001$ and $P<0.001$, respectively.

${ }^{\mathrm{b}}$ Range of AHI values for the given kernel weight subclass.

c Range of SKCS values for the given kernel weight subclass.

d Range of kernel diameter for the given kernel weight subclass.

e Number of samples in a given kernel weight subclass.

TABLE IV

Correlations Between Single Kernel Characterization System Hardness Index (SKCS-HI) and Abrasive Hardness Index (AHI) for Kernel Diameter Subclasses

\begin{tabular}{|c|c|c|c|c|}
\hline & \multicolumn{4}{|c|}{ Diameter Subclasses } \\
\hline & $1.4-1.79 \mathrm{~mm}$ & $1.8-2.09 \mathrm{~mm}$ & $2.1-2.39 \mathrm{~mm}$ & $>2.4 \mathrm{~mm}$ \\
\hline$r^{\mathrm{a}}$ & $0.65 *$ & $0.76^{* *}$ & $0.68 *$ & $0.56^{*}$ \\
\hline AHI range ${ }^{b}$ & $8-22$ & $6-19$ & $7-18$ & $8-17$ \\
\hline AHI average & 12 & 11 & 11 & 11 \\
\hline SKCS range $^{c}$ & $37-125$ & $35-111$ & $34-93$ & $48-90$ \\
\hline SKCS average & 92 & 79 & 72 & 76 \\
\hline Weight range $(\mathrm{mg})^{\mathrm{d}}$ & $16-22$ & $17-28$ & $23-36$ & $25-37$ \\
\hline Weight average (mg) & 21 & 23 & 29 & 31 \\
\hline$n^{\mathrm{e}}$ & 21 & 29 & 29 & 22 \\
\hline
\end{tabular}

${ }^{a}$ Correlation between SKCS-HI and AHI: ** and * indicate $P<0.0001$ and $P<0.001$, respectively.

${ }^{\mathrm{b}}$ Range of AHI values for the given kernel weight subclass.

c Range of SKCS values for the given kernel weight subclass.

${ }^{\mathrm{d}}$ Range of kernel diameter for the given kernel weight subclass.

e Number of samples in a given kernel weight subclass.

such relationships differ from AHI values, we felt the SKCS should not be calibrated to AHI. Research into using the crush profiles generated by SKCS to predict AHI is in progress. It may be possible to generate both a unique SKCS hardness measure and at the same time predict an AHI value.

\section{CONCLUSIONS}

This study builds on the work of Pedersen et al (1996) in demonstrating the applicability of the SKCS for characterizing sorghum kernel properties. SKCS predictions of weight, diameter, and moisture for sorghum grain were evaluated and compared with standard laboratory methods. The SKCS accurately predicted weight relative to weight kernels on an analytical balance. SKCS predictions of kernel thickness (diameter) were highly correlated to digital caliper measurements, though the SKCS underestimated the value by $\approx 20 \%$. SKCS predictions of moisture were also correlated to moisture as measured by an air oven method, but again the SKCS predictions underestimated the moisture relative to the air oven moisture measurements. New slope and bias values were developed to adjust the SKCS predictions for diameter and moisture to match the laboratory values. New slope and bias values for kernel rejection criteria were also developed. The SKCS can be used to predict sorghum grain hardness without modification. SKCS hardness values were compared with AHI values. There was a moderate correlation $(r=0.61)$ between the two hardness indices, though at high AHI values, some nonlinearity between the two measurements was noted. The SKCS can provide rapid hardness measurements of sorghum grain and provide information on the variability present in a sample, making the SKCS a valuable tool for assessing sorghum grain characteristics. Future work should focus on instrument-to-instrument variability for sorghum, improving moisture slope and bias corrections, and determining how the SKCS hardness values relate to processing and end-use traits in sorghum.

\section{ACKNOWLEDGMENTS}

We would like to acknowledge the assistance of Charles Martin in helping with data analysis for this project and Brian Ioerger for technical assistance in analyzing samples.

\section{LITERATURE CITED}

Aboubacar, A., and Hamaker, B. 1999. Physiochemical properties of flours that relate to sorghum couscous quality. Cereal Chem. 76:308313.

ASAE. 2003. Moisture measurement-Unground grain and seeds. ASAE Standard S352.2. ASAE: St. Joseph, MI.

Audilakshimi, S., Stenhouse, J. W., Reddy, T. P., and Prasad, M. V. R. 1999. Grain mould resistance and associated characters of sorghum genotypes. Euphytica 107:91-103.

Awika, J. M., Gualberto, D., Rooney, L. W., and Rooney, W. L. 2002. Properties of white food sorghums grown in different environments. AACC 87th Annual Meeting. Abstract published online at http://www. scisoc.org/aacc/meeting/2002. AACC International: St. Paul, MN.

Bettge, A. D., and Morris, C. F. 2000. Relationships among grain hardness, pentosan fractions, and end-use quality of wheat. Cereal Chem. $77: 241-247$.

Cagampang, G. B., and Kirleis, A. W. 1984. Relationship of sorghum grain hardness to selected physical and chemical measurements of grain quality. Cereal Chem. 61:100-105. 
Chandrashekar, A., and Mazhar, H. 1999. The biochemical basis and implications of grain strength in sorghum and maize. J. Cereal Sci. 30:193-207.

Hart, J., Feinstein, L., and Golumbic, C. 1959. Oven methods for precise measurement of moisture in seeds. Marketing Research Report 304. U.S. Government Printing Office: Washington, D. C.

Jambunathan, R., Kherdekar, M. S., and Stenhouse, J. W. 1992. Sorghum grain hardness and its relationship to mold susceptibility and mold resistance. J. Agric. Food Chem. 40:1403-1408.

Kirleis, A. W., and Crosby, K. D. 1982. Sorghum hardness: Comparison of methods for its evaluation. Pages 231-241: in Proc. Int. Symp. on Sorghum Grain Quality. ICRISAT: Patancheru, India.

Kumari, S. R., and Chandrashekar, A. 1994. Relationships between grain hardness and the contents of prolamin and three anti-fungal proteins in sorghum. J. Cereal Sci. 20:93-99.

Lawton, J. W., and Faubion, J. M. 1989. Measuring kernel hardness using the tangential abrasive dehulling device. Cereal Chem. 66:519-524.

Lee, W., Pedersen, J., and Shelton, D. 2002. Relationship of sorghum kernel size to physiochemical, milling, pasting, and cooking properties. Food Res. Int. 35:643-649.

Martin, C. R., and Steele, J. L. 1996. Evaluation of rotor-crescent design for sensing wheat kernels hardness. Trans. ASAE 39:2223-2227.

Martin, C. R., Rousser, R., and Brabec, D. L. 1993. Development of a single-kernel wheat characterization system. Trans. ASAE 36:1399-1404.

Maxon, E. D., Fryar, W. B., Rooney, L. W., and Krishnaprasad, M. N. 1971. Milling properties of sorghum grain with different proportions of corneous to floury endosperm. Cereal Chem. 48:478-490.

Munck, L. 1995. New milling technologies and products: Whole plant utilization by milling and separation of the botanical and chemical components. Pages 223-281 in: Sorghum and Millets: Chemistry and Technology. D. A. V. Dendy, ed. AACC International: St. Paul, MN.
Munck, L., Bach Knudsen, K. E., and Axtell, J. D. 1981. Milling processes and products related to kernel morphology. Pages 200-210 in: Proc. Int. Symp. on Sorghum Grain Quality. L. W. Rooney and D. S. Murphy, eds. ICRISAT: Patancheru, India.

Oomah, B. D., Reichert, R. D., and Youngs, C. G. 1981. A novel, multisample, tangential abrasive dehulling device (TADD). Cereal Chem. 58:392-395.

Osborne, B. G., and Anderssen, R. S. 2003. Single-kernel characterization principles and applications. Cereal Chem. 80:613-622.

Panozzo, J. F., and Ratcliffe, M. 1997. Application of the single kernel characterization system and its relationship with barley quality. Pages 320-322 in: Proc. 8th Australian Barley Technol. Symp. ABTS: Brisbane.

Pedersen, J. F., Martin, C. R., Felker, F. C., and Steele, J. L. 1996. Application of the single kernel wheat characterization technology to sorghum grain. Cereal Chem. 73:421-423.

Pomeranz, Y. 1986. Comparison of screening methods for indirect determination of sorghum hardness. Cereal Chem. 63:36-38.

Rooney, L. W., and Waniska, R. D. 2000. Sorghum food and industrial utilization. Pages 689-750 in: Sorghum: Origin, History, Technology, and Production. C. W. Smith and R. A. Frederiksen, eds. John Wiley and Sons: New York.

Rooney, L. W., Kirleis, A. W., and Murty, D. S. 1986. Traditional foods from sorghum: Their production, evaluation, and nutritional value. Pages 317-353 in: Advances in Cereal Science and Technology. Vol. 8. Y. Pomeranz, ed. AACC International: St. Paul, MN.

Waniska, R. 2000. Structure, phenolic compounds, and anti-fungal proteins of sorghum caryopsis. Pages 72-106, in: Technical and Institutional Options for Sorghum Grain Mold Management. Proc. Int. Consultation. A. Chandrashekar, R. Bandyopadhyay, and A. J. Hall, eds. ICRISAT: Patancheru, India.

[Received May 3, 2005. Accepted September 21, 2005.] 